7-15-2020

\title{
Important lessons on FGM/C abandonment from four research studies in Egypt
}

Nada Wahba

Population Council

Nahla G. Abdel-Tawab

Population Council

Abeer Salem

Population Council

Follow this and additional works at: https://knowledgecommons.popcouncil.org/departments_sbsr-rh

Part of the Demography, Population, and Ecology Commons, Family, Life Course, and Society Commons, Gender and Sexuality Commons, International Public Health Commons, and the Medicine and Health Commons How does access to this work benefit you? Let us know!

\section{Recommended Citation}

Ramadan, Nada, Nahla G. Abdel-Tawab, and Abeer Salem. 2020. "Important lessons on FGM/C abandonment from four research studies in Egypt," Evidence to End FGM/C: Research to Help Girls and Women Thrive. New York: Population Council. 


\section{Important Lessons on FGM/C Abandonment from Four Research Studies in Egypt}

The Evidence to End FGM/C programme consortium generates evidence to inform and influence investments, policies, and programmes for ending female genital mutilation/ cutting in different contexts.

Population Council Lead Institution

Africa Coordinating Centre for the Abandonment of Female Genital

Mutilation/Cutting, Kenya (ACCAF)

Global Research and Advocacy Group, Senegal (GRAG)

MannionDaniels Ltd. (MD)

Population Reference Bureau (PRB)

University of Washington (Prof. Bettina Shell-Duncan)

University of California, San Diego (Dr. Gerry Mackie)

\section{Funded by}

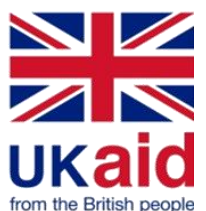

\section{Background}

Female genital mutilation/cutting (FGM/C) continues to be a widespread practice in Egypt. According to the 2014 Egypt Demographic and Health Survey (EDHS), the prevalence rate of FGM/C was $92 \%$ among ever-married women aged 15 to 49 (MOPH, El-Zanaty and Associates, and ICF International 2015a). However, Egypt continues to witness a drastic surge in the medicalisation of $\mathrm{FGM} / \mathrm{C}$ in Egypt, with $74 \%$ of women aged 19 years and younger circumcised by medical practitioners, compared to 55\% in 1995 for women in the same age group (MOPH, El-Zanaty and Associates, and ICF International 2015a).

This policy brief provides key results and recommendations of four studies that were conducted by the Population Council/ Egypt under the Evidence to End FGM/C project, in coordination with Egypt's National Population Council. The four studies aimed to (i) investigate the process through which families reach a decision on FGM/C; (ii) study the impact of $F G M / C$ campaigns on the perspectives surrounding the practice; (iii) examine the characteristics of abandoners and challenges they face in maintaining their position; and (iv) understand the drivers of the medicalisation of the practice. The ultimate goal of the four studies is to assist the National Taskforce for Ending Female Genital Mutilation/Circumcision in developing evidence-based policies and programmes to accelerate the abandonment of FGM/C.
The first three studies used mixed methods, i.e., secondary analysis of quantitative data sets such as EDHS 2014, SYPE 2014, and the Egypt Health Issues Survey (EHIS) 2015 as well as focus group discussions (FGDs) and / or in-depth interviews (IDI). The fourth study used mystery clients ${ }^{1}$ in addition to focus group discussions and in-depth interviews. Studies were conducted between 2016 and 2019. All research instruments were reviewed by a steering committee that was headed by the National Population Council.

\section{Key findings}

\section{\# 1: A key driver of the persistence of $\mathrm{FGM} / \mathrm{C}$ is that it is still associated with women's marriage prospects and life options. Parents base most of their decisions concerning the upbringing of their daughters on how the daughters will be viewed by others in the community. $\mathrm{FGM} / \mathrm{C}$ is done mostly to secure daughters' marriage prospects. Findings also reflected that almost all parents view daughters as weak, unable to survive independently, and in need of protection. Even parents who were supportive of girls' education did not view it as a girl's right or an asset in and of}

\footnotetext{
${ }^{1}$ Mystery clients are trained researchers who visited participating physicians' clinics, and act as if they are either undecided about cutting their daughters or determined to cut their daughters. The researchers then recorded the responses of the physicians in the two scenarios. All participating physicians were selected from a larger pool of those who signed an informed consent, accepting a visit by a "mystery client" sent by the governorates' health directorates to assess the quality of reproductive health counselling, for research purpose only, with ensured confidentiality.
} 
itself, but as a vehicle for better marriage prospects (Galal et al. forthcoming)

"People around here look for girls (i.e., brides) who are educated, who have a diploma. They are in demand. However, there is no demand for ignorant girls who have no education." - Father, FGD, Rural Gharbia

The centrality of marriage as a measure of success for girls exacerbates the perceived need to circumcise, as was clarified across several studies, as the practice is linked to chastity, reputation, and marriage prospects. In explaining why girls are sometimes forced to get cut before they are married, one mother explained:

"People would repeatedly tell [the husband] 'your wife is uncircumcised.' The whole village knows each other and knows who is and who is not circumcised."- Mother, FGD, Assiut

\section{\#2: Men's beliefs and preferences are a driving} force in the culture that sustains FGM/C. Men interviewed as part of the qualitative study also seemed to focus largely on the sexual repercussions of the practice. Narratives from all four studies reveal that one of the main reasons circumcision is sustained is to ensure that women are not "hypersexual," yet still retain some libido and pleasure so their husbands do not feel that they are too frigid. This narrative is driven by the needs and opinions of men, even when it is sustained by women.

The opinions of male participants in the studies varied. Some men were against circumcision, mentioning that it makes women too cold during sexual intercourse. Others were for it as they only wanted women to have a limited amount of sexual libido and pleasure during intercourse, which they believed can be accomplished through circumcision.

"FGM/C creates problems between married couples. I got married twice and in my first marriage, there was sexual coldness between me and my wife. But if the woman is wholesome, that is a totally different story. If I did this to my girl, I would be humiliating her." -Father, IDI, Urban Gharbeya

"The girl, if she doesn't get cut, her sexual drive overrides that of a man. That's why a girl needs to be cut and that's according to 'Sunna.' People usually say that is what our parents raised us on. So as I'm telling you a girl needs to be cut and at a young age."-Father, IDI, Cairo
Mothers also seemed to be concerned with men's preferences and often noted that sexual frigidity, or overexcitement, can cause marital complications for a woman and her husband. This dilemma was underlying some of the confusion and hesitation in the decision of whether or not to cut their daughters.

"I have some colleagues who are circumcised and some who are not. And I hear about those who are not circumcised; that her husband can't deal with her and he can't stand it so they're going to divorce. At the same time, I hear about one who is sexually frigid, and her husband can't stand [sex] with he.... He says, 'no I don't feel any feelings with her....She's unable to reciprocate any sensations.' I mean, it's a double-edged sword."-Girl, IDI, Rural Gharbia

"When a girl gets married and she's cut-extremely cut-about three-quarters of men complain about her.... It eventually affects the marital relations....and he ends up leaving her or marrying another woman...." Mother, IDI, Cairo

\section{\# 3: $\mathrm{FGM} / \mathrm{C}$ is perceived as acceptable when} performed in a certain manner, and if performed by a medical practitioner. In all four studies it emerged that some participants state that they are against FGM/C, yet they cut their daughters. For these participants, they view the traditional form of FGM/C as the harmful practice and not the type practised by medical professionals. At the same time, medical professionals are offering "cosmetic surgery" to parents as a safe and modern procedure.

"Based on what l've seen on the internet, it's called a cosmetic surgery, not called circumcision, OK?... I told [my daughter] 'if there's anything, we can catch it and have a cosmetic surgery'... and [my daughter] said, 'No, are you kidding me, isn't this circumcision?' So, I said 'No, I'm not talking about that of course, there's a difference."'-Mother, IDI, Cairo

The language used to describe the practice is being reframed by healthcare providers as cosmetic surgery (El-Gibaly, Aziz, and Abou Hussein 2019). It is likely that providers rely on such terms to free themselves of the blame directed towards the physicians when cutting girls. Providers claimed that in most cases, they only cut the labia minora and not the clitoris, except when the clitoris was enlarged and protruded out of the labia minora.

Many families are also convinced that their daughters may need cosmetic surgery, which usually involves making a less intrusive cut: 
"I don't call it circumcision, I call it 'refinement.' For me, as a doctor, I don't do this case as female circumcision, I do it as a technical case. For example, after the age of 16 to 17, when everything is clear and there are problems from it, so I do this refinement or cosmetic operation."-Male physician, Gharbeya

Some families do not associate the safe and "civilized" medically authorised form of the practice with what has been portrayed as an ignorant and violent procedure. Mothers recalled the trauma of their own procedures as one of the main reasons why they do not want to circumcise their daughters. The belief that medicalised FGM/C is acceptable because trauma can be minimised through sedation or painkillers can hinder abandonment, with mothers not having the same motivation to protect their daughters from the trauma that they experienced (El-Gibaly, Aziz, and Abou Hussein 2019).

"She could go into a psychological trauma; she could be traumatized from what happened to her. That is if it was done to her by a normal person [daya] and not a doctor. Some people do it without anaesthesia and as such she could go into an intense psychological trauma...."-Girl, IDI, Cairo

\section{\# 4: There is a belief that there could be a "need" for circumcision, and doctors are perceived to "know" whether the practice is necessary. The majority of participants across all four studies believed that there is sometimes a need for circumcision. In some instances, this was related to a girl's behaviour. In other cases, it was believed that a girl could be too sexually demanding of her husband when she gets married. In yet other cases, her genitalia were considered too big and hence needed "refinement."}

"No, I honestly didn't take them [her daughters] to a doctor... because they're good and tame.... if I saw her eyeing [men], talking to guys or something, I'd know she has tendancies towards [inappropriate behaviour] so l'd take her to be checked by a doctor... The medical experts can then do what they see fit."-Mother, IDI, Cairo

This need for circumcision still seemed confusing to many participants, and some hesitant mothers who were prone to abandonment still decided to consult a physician, to remove the burden of taking a complicated decision by themselves. Very few abandoners, across all four studies, had decided not to circumcise their daughters without consulting a physician.
"I started thinking about it a bit more.... I started reading more and understanding more... Now my thinking is that if a girl goes to a doctor and the doctor says it's needed then, yes, she should go get cut."-Girl, IDI, Rural Gharbia

Physicians often performed FGM/C for different reasons. First, some physician seemed to lack awareness themselves, and the knowledge they have about FGM/C is passed on to them by fellow physicians. They mentioned that while they were not instructed how to perform it during their studies, each physician had his/her own idea about whether there is a "proper" way to perform the practice, and what that way is (El-Gibaly, Aziz, and Abou Hussein 2019).

"Nothing in medicine taught us how to perform [FGM/C], and I didn't study it during my years of education. Whether cutting from the right or from the left, it is personal." Male physician, Assiut

Other physicians explained that financial benefit is the most important motivator for performing the practice (El-Gibaly, Aziz, and Abou Hussein 2019).

"More than 50 percent of the doctors in the rural areas do these things for several reasons. First for financial gains and trust of people that he [the doctor] responded to their needs and they will come to him for other matters. And if he does not do it, he will be stigmatised." Male physician, Cairo

In other cases, providers' convictions-based on religion or culture-regarding FGM/C were another driving factor that pushes them to cut girls (ElGibaly, Aziz, and Abou Hussein 2019).

\section{\# 5: Mothers are the key players in the practice} of FGM/C; however, fathers are becoming increasingly involved. While grandmothers, aunts, and fathers all have an impact on the decision to circumcise, mothers remain the primary decisionmakers when it comes to FGM/C. What this means in practise, is that they shoulder the responsibility of being more informed on the topic, in speaking with friends and neighbours, consulting medical practitioners, and arranging the logistics of how and where the practice will be carried out if they choose to circumcise (Galal et al. forthcoming).

Qualitative results have shown that men are less likely to be well-informed on the topic of FGM/C, and, as mentioned, still consider this a woman's domain and rely on their wives to do most of the legwork of the decision. 
With the medicalisation of the practice, however, the involvement of fathers in the final decision is increasing. First, because medicalized FGM/C is frequently performed outside the home, which often necessitates permission from the husbands before leaving the house. Second, because the practice is more expensive if done by a doctor and hence fathers in most cases are expected to pay for it.

"I need to get my husband's permission; he is going to pay for it [cutting]. He has to know where I am going and why."-Mother, FGD, Urban Sohag

Results also show that if either of the spouses chooses to abandon the practice, it is likely that the girl will not be circumcised. To elaborate, results from the Gender and Decision-making Study have shown that if there is a disagreement on whether or not to circumcise their daughter, the spouse who is for abandonment is likely to win the argument. In focus group discussions (FGDs) and in-depth interviews (IDIs) conducted as part of the gender and decisionmaking study in Cairo, Gharbeya, and Souhag, two mothers refused to cut their daughters whereas their husbands supported the practice. Both women seemed to have won the argument and managed to make the final decision on FGM/C abandonment. On the other hand, there were four cases of mothers wanting to cut their daughters who had to give in to their husbands' request to not having their girls cut.

\section{\# 6: In some cases, adolescent girls may be able to influence the FGM/C decision for} themselves or their younger siblings. According to results across all four studies, the age of FGM/C may be increasing, as some medical practitioners ask parents who approach them to come back in a few years as it is too early to determine if the girl needs to be circumcised. If parents are told to come back, it allows some time in which to intervene with parents on changing their views on the practice. In some cases, there may be an option for an older daughter to influence the parents' decisionmaking, as in the case of three daughters from Urban Gharbia. The first two were circumcised, but the eldest convinced her mother not to cut their youngest sister. The middle sister explained:

\footnotetext{
"My younger sister was not cut because my older sister told my mother not to cut her. Her circumcision had really left a mark on her."-Girl, IDI, Rural Gharbia
}

While daughters themselves are seldom involved in the decision to get cut, many who found out that they were going to be cut tried to resist. However, they were often unable to. Some had little idea of why they were being brought to the clinic, and were not aware that the surgical procedure was considered FGM/C. Most also had little knowledge of the negative short- and long-term consequences of the practice.

"There were ads on television and other things of the sort [on FGM/C], only at that time (when I was at the clinic) did I begin to link what happened during the procedure and what I had been seeing.... I hadn't heard of it as a surgical procedure, but I would always see flyers that say 'No to FGM/C."'-Girl, IDI, Rural Gharbia

\section{\# 7: While the FGM/C law has been strengthened, awareness of the law remains} limited and the law itself is not enough to lead to abandonment. FGM/C has been criminalised in Egypt since 2008 and the penalty was made stricter in 2016. Under the current law, practitioners of $\mathrm{FGM} / \mathrm{C}$ are sentenced to an imprisonment period ranging from 5-7 years, along with an imprisonment penalty ranging from 1-3 years for an individual (e.g., parent) who escorts the victims of such crimes to the perpetrators (28TooMany 2017).

Results from our studies showed that the public was not aware of the law. A few study participants expressed familiarity with certain aspects of the law against FGM/C (i.e., who is prosecuted, where it is enforced). However, the law was not highlighted as the primary deterrent for abandonment for any of the families included, and it was not mentioned by participants as often as religious and medical factors.

However, there were some cases where the law acted as a deterrent if there are already other motivations to abandon. "I don't circumcise girls. First, this is criminalised by
law and the penalty has been also increased
recently. Second, it has no indications and has
nothing to do with sexual purity." Female physician,
Assiut

Aside from a lack of awareness of the law, and its low effect on deterrence from the practice, some believe that the law will not be enforced unless the practice leads to death. 
"Prosecutors usually take a case not because a girl underwent an FGM/C procedure but because the girl died during the procedure."-Male physician, Cairo.

\section{\# 8: Media campaigns have been successful in} raising awareness of some consequences of the practice but were not sufficient in changing attitudes and behaviours towards it. The percentage of people who reported exposure to mass media messages on $\mathrm{FGM} / \mathrm{C}$ was $73 \%$ in 2008 and only 35\% in 2014 (MoHP, El-Zanaty and Associates, and ICF International 2015a). Most study participants mentioned that inconsistent mass media messaging, both in frequency and content, has made it difficult for a sustainable impact on people's opinions, and have pushed people to hesitation rather than full abandonment.

Fathers and young men found some of the messaging to be unconvincing:

"The [media] spots are full of girls crying, of a lot of darkness. There is none of this in reality."-Male physician, Gharbia

Participants also explained that the campaigns were not informative enough and did not explain in detail the less severe consequences of the practice. Several men added that they had not heard of the fatwa (Islamic ruling) issued on the practice and were not sure of the religious standpoint on the practice.

Community seminars were seen as spaces for direct communication and a chance to ask questions and get answers. Reflecting on this point, a father from rural Souhag mentioned,

"Sessions are generally better because lecturers address your questions directly. If I sit in front of a television advertisement, there is a higher possibility that I may daydream or not comprehend what is being said." Father, Souhag.

\section{Recommendations}

1. Tackle the roots of the practice

- Efforts to abandon FGM/C should adopt a comprehensive approach, that aims to tackle the reasoning underlying the practice, change attitudes of parents to raise their daughters to be independent; and works towards women's economic independence and dissociates their success and security from their marriage prospects.

- Awareness-raising campaigns need to address the underlying rationale and misconceptions about the need for FGM/C, regarding women's sexuality and behaviour. This encompasses highlighting the negative consequences of the practice including the negative effects of the practice on sexual satisfaction of both men and women when women have undergone FGM/C.

2. Address the ways in which the practice is adapting

- When speaking about FGM/C in awarenessraising campaigns, messages should clarify that "cosmetic surgery" is still FGM/C, and that all forms of FGM/C need to be abandoned.

- It is important to educate medical practitioners about female genitalia and sexuality, highlighting that there is no right size, shape, or form that makes female genitalia normal. This information should also be addressed in awareness-raising campaigns targeting parents and communities and should be integrated into secondary school curricula.

- As doctors are often left to be decisionmakers by parents, their financial incentives, and other motivations to perpetuate the practice need to be examined.

- When designing research surveys and interview guides, it is important to clarify to participants what exactly is meant by "circumcision" to ensure that the results of these surveys are accurate and capture all the practices that involve cutting of the female genitalia, even for cosmetic reasons. 
3. Increase access to information to all family members

- Awareness-raising campaigns should target all members of the family, including fathers who are becoming more involved in the decision to cut their daughters. It is important to take into consideration that while mothers remain more involved in the decision on whether or not to circumcise, either of the spouses can be allies towards abandoning the practice if they have strong opinions against it. While the reach of mass media messaging may be wide, careful pretesting and evaluation of impact of mass media investments are needed. Additionally, interactive fora may be more acceptable and impactful.

- Young women and men should have more access to information and awareness. This could be done through integrating sexual and reproductive health into school curricula, addressing young women in TV advertisements and community seminars, as well as using social media to provide a platform where the topic can be discussed and information can be made available.

- The Child Protection hotline should be made known to all community members, including young women, who might be able to report an expected $\mathrm{FGM} / \mathrm{C}$ procedure for themselves or their siblings.

4. Implement the law regardless of the outcome or the name of the procedure

- The legal consequences of the practice need to be dissociated from death as a result of the procedure and should be linked to the procedure in itself. In order to do so, medical practitioners need to be prosecuted for performing the practice even if the girl does not die or suffer complications. Awareness-raising campaigns and medical school curricula need to clarify this, and the public should be encouraged to report medical practitioners who perform the practice, regardless of whether the girl suffers complications from it.

- Hospitals and clinics need to be more closely monitored, keeping in mind that $\mathrm{FGM} / \mathrm{C}$ is often performed under various names, including under the cover of cosmetic surgery.

\section{References}

28TooMany. 2017. Egypt Country Profile.

Abou Hussein, S. and S. Ghattas. 2019. No to Circumcision: The Road to Effective Social Marketing Campaigns in Egypt. Evidence to End FGM/C: Research to Help Girls and Women Thrive. New York: Population Council.

El-Gibaly, O., M. Aziz, and S. Abou Hussein. 2019. "Health care providers' ad mothers' perceptions about the medicalization of female genital mutilation or cutting in Egypt: A cross-sectional qualitative study," BMC International Health and Human Rights, 19(1).

Galal, S., S. Keller, S. Abou Hussein, and N. Wahba. Forthcoming. Female Genital Mutilation/Cutting Decision-making Process and the role of Gender Power Relations in Egypt. Evidence to End FGM/C: Research to Help Girls and Women Thrive. New York: Population Council.

Ministry of Health and Population [Egypt] (MOHP), El-Zanaty and Associates [Egypt], and ICF International. 2015a. Egypt Demographic and Health Survey 2014. Cairo, Egypt and Rockville, MD: MOHP and ICF International. 2015b. Egypt Health Issues Survey 2015. Cairo, Egypt and Rockville, MD: MOHP and ICF International. Available at: https://dhsprogram.com/pubs/pdf/FR313/FR313.pdf

Ismail, S., N. Abdel-Tawab, and L. Sheira. 2015. Health of Egyptian Youth in 2014: Knowledge, Attitudes and Behaviors in Panel Survey of Young People in Egypt 2014: Generating Evidence for Policy, Programs and Research. Cairo: Population Council.

Wahba, N., H. El Banhawi, and A. El Ayouti. Forthcoming. Improved Understanding of Female Genital Mutilation/Cutting Abandonment in Egypt. Evidence to End FGM/C: Research to Help Girls and Women Thrive. New York: Population Council.

Suggested Citation: Wahba N., Abdel-Tawab N., and Salem A. 2020. Important Lessons on FGM/C Abandonment from Four Research Studies in Egypt. Evidence to End FGM/C: Research to Help Girls and Women Thrive. New York: Population Council. 
ANNEX: Research objectives and methodology of the four studies

\begin{tabular}{|c|c|c|c|c|}
\hline Study Title & Study Objectives & Methodology & $\begin{array}{l}\text { Governorates } \\
\text { (for qualitative } \\
\text { data collection) }\end{array}$ & $\begin{array}{c}\text { Quantitative } \\
\text { datasets } \\
\text { used }\end{array}$ \\
\hline $\begin{array}{l}\text { "No to Circumcision": } \\
\text { The Road to Effective } \\
\text { Social Marketing } \\
\text { Campaigns in Egypt }\end{array}$ & $\begin{array}{l}\text { Understand how, where, and why } \\
\text { social marketing campaigns for } \\
\text { FGM/C abandonment are working } \\
\text { and study their impact in order to } \\
\text { design and scale up campaigns } \\
\text { that can foster new perspectives, } \\
\text { expectations, and behaviours. }\end{array}$ & $\begin{array}{l}\text { Quantitative } \\
\text { secondary } \\
\text { analysis and } \\
\text { primary } \\
\text { qualitative data } \\
\text { (FGDs and IDIs) }\end{array}$ & $\begin{array}{l}\text { Al Gharbia, } \\
\text { Cairo, Suhag }\end{array}$ & EDHS, SYPE \\
\hline $\begin{array}{l}\text { Medicalisation of } \\
\text { FGM/C in Egypt: } \\
\text { Perspectives of } \\
\text { Health Care Providers } \\
\text { and Mothers }\end{array}$ & $\begin{array}{l}\text { Examine the drivers (demand and } \\
\text { supply) of the continuation of } \\
\text { FGM/C practise by healthcare } \\
\text { providers, as well as the drivers of } \\
\text { abandonment. }\end{array}$ & $\begin{array}{l}\text { Based on } \\
\text { primary } \\
\text { qualitative data } \\
\text { (FGDs and IDIs) }\end{array}$ & $\begin{array}{l}\text { Al Gharbia, } \\
\text { Assiut, Cairo }\end{array}$ & \\
\hline $\begin{array}{l}\text { Decision-making } \\
\text { Process and the Role } \\
\text { of Gender Power } \\
\text { Relations in Egypt }\end{array}$ & $\begin{array}{l}\text { Determine key decisionmakers on } \\
\text { FGM/C, examine the processes } \\
\text { by which families reach the } \\
\text { decision, and assess the role of } \\
\text { gender attitudes in decision- } \\
\text { making. }\end{array}$ & $\begin{array}{l}\text { Quantitative } \\
\text { secondary } \\
\text { analysis and } \\
\text { primary } \\
\text { qualitative data } \\
\text { (FGDs and IDIs) }\end{array}$ & $\begin{array}{l}\text { Al Gharbia, } \\
\text { Cairo, Suhag }\end{array}$ & $\begin{array}{l}\text { EDHS, EHIS, } \\
\text { SYPE }\end{array}$ \\
\hline $\begin{array}{l}\text { Improved } \\
\text { Understanding of } \\
\text { FGM/C Abandonment }\end{array}$ & $\begin{array}{l}\text { Understand the characteristics of } \\
\text { abandoners, the challenges they } \\
\text { have faced in abandoning } \\
\text { FGM/C, and factors which may } \\
\text { have helped them maintain their } \\
\text { abandonment position. }\end{array}$ & $\begin{array}{l}\text { Quantitative } \\
\text { secondary } \\
\text { analysis and } \\
\text { primary } \\
\text { qualitative data } \\
\text { (FGDs and IDIs) }\end{array}$ & $\begin{array}{l}\text { Al Gharbia, } \\
\text { Cairo, Suhag }\end{array}$ & \\
\hline
\end{tabular}

